DOI: 10.12731/2077-1770-2020-4-361-373

УДК 811.161.1

\title{
ИНВАРИАНТ СЛОВООБРАЗОВАТЕЛЬНОГО ТИПА КАК СРЕДСТВО СИСТЕМАТИЗАЦИИ ПРОИЗВОДНОЙ ТЕРМИНОЛОГИЧЕСКОЙ ЛЕКСИКИ ДИЗАЙНА
}

\section{Шонтукова И.В.}

Актуальность статьи заключается в поиске новых способов систематизации лексики. Целью является рассмотрение лингводидактической единицы Инвариант словообразовательного типа в качестве средства комплексной систематизачии производной терминологической лексики на примере профессиональной лексики дизайна.

Методы или методология исследования. В процессе исследования применяются такие методы, как анализ научных источников и моделирование производных слов. В частности, автор проводит анализ существующих научных трудов в области терминообразования и классификации лексики и приводит собственный опыт изучения профессиональной дизайнерской лексики. Основное содержание статьи посвящено описанию использования технологии построения словообразовательных моделей производной лексики в качестве средства систематизации дизайнерских терминов.

Результаты исследования заключаются в определении основных групп терминов, относящихся к сфере дизайна, выделении наиболее продуктивных типов производной дизайнерской лексики, схем и словообразовательных моделей производных терминов дизайна. Делается основной вывод о том, что Инвариант словообразовательного типа может быть использован в качестве средства систематизации терминологической лексики в силу ее специфических свойств.

Область применения результатов. Предложенный способ систематизачии позволит проводить комплексный анализ родственных лингвистических явлений в образовании терминологический лексики.

Ключевые слова: инвариант словообразовательного типа; систематизация производной лексики; терминологическая лексика дизайна. 


\section{WORD-FORMATION INVARIANT \\ AS A MEANS OF SYSTEMATIZATION OF DERIVED TERMINOLOGICAL VOCABULARY}

\section{Shontukova I.V.}

The relevance of the article is to find new ways to systematize the vocabulary. The purpose of the study is to consider the linguodidactic unit Invariant of the word-formation type as a means of complex systematization of derived terminological vocabulary on the example of professional vocabulary of design.

Methods or methodology of work. The analysis of scientific sources and modeling of derived words are applied. In particular, the author analyzes existing scientific works in the field of term formation and classification of vocabulary and gives her own experience of studying professional design vocabulary. The main content of the article is devoted to the description of the use of technology for building word-formation models of derived vocabulary as a means of systematization of design terms.

The result of the study is defining the main terms related to the field of design, the most productive types of derived design vocabulary, word-formation schemas and models of the derived terms of design. The main conclusion is made that the word-formation type Invariant can be used as a means of systematization of terminological vocabulary due to its specific properties.

Practical implications. The proposed method of systematization will allow for a comprehensive analysis of related linguistic phenomena in the formation of terminological vocabulary.

Keywords: invariant of word formation type; systematization of derived vocabulary; terminological vocabulary of design.

\section{Введение}

Проблема образования, классификации и систематизации терминологической лексики давно находит свое отражение в различных исследованиях. В части изучения сути и способов образования терминов можно отметить труды Г.О. Винокура [4], Б.Н. Головина 
[6], Х. Бахарлу, Ш.М. Алияри, М. Шоджаи [1], А.Э. Буженинова [2], В.С. Воропаевой [5], В.М. Лейчик [9], Д.С.Лотте [11], С.В. Гринева-Гриневича [7]. Вопросы лингводидактики в изучении и систематизации терминологической лексики раскрывают О.А. Васильева [3], Г.А. Мкртчян [12]. При этом, многие обращают внимание на морфологический способ образования терминов (прежде всего путем словообразования) как самый продуктивный: О.А. Васильева [3], Г.А. Мкртчян [12], В.Н. Семичев [14].

Большое внимание уделяется и вопросам систематизации терминов. Так, Каргина отмечает, что «психологические исследования также свидетельствуют о том, что слова более эффективно запоминаются, если они соединены друг с другом некоторыми систематическими закономерностями и предъявляются обучающимся в виде определенной системы (определенной последовательности и сочетаемости)» [8]. При этом она в качестве основного использует способ объединения терминов в лексико-семантические группы, что является весьма популярным в научной литературе, посвященной изучению терминологии любой профессии.

В.И. Литовченко рассматривает различные подходы к классификации и систематизации терминов, приводит классификацию в изучении терминологии через построение иерархических систем классов и их подклассов на основе некоторых признаков, не являющихся собственными объектами или присущими им [10].

В целом, можно говорить о том, что современное языкознание предлагает различные способы и средства для систематизации лексики, которые находят отражение, прежде всего, в разных типах словарей. Большая часть словарей ориентирована на алфавитный принцип систематизации (орфографические, орфоэпические, толковые, энциклопедические и др.), что оправдано их целями и задачами. Однако встречаются словари и пособия, придерживающиеся иных принципов систематизации лексики: тематического, морфемно-словообразовательного, гнездового и др.

Целью данной статьи является рассмотрение возможностей использования Инварианта СТ в комплексной систематизации терми- 
нологической и профессиональной лексики на примере лексики дизайна. Предлагаемый автором статьи подход является в достаточной степени новым именно с точки зрения применения его как метода лингвистической классификации производной лексики. В процессе работы автор ставил ряд задач:

- определить основные группы терминов, относящихся к сфере дизайна;

- определить наиболее продуктивные типы производной дизайнерской лексики;

- проиллюстрировать способ систематизации производной лексики посредством построения словообразовательных моделей.

\section{Материалы и методы}

Нам представляется, что выведенная М.Ш. Шекихачевой в 1978 г. лингводидактическая единица - инвариант словообразовательного типа - также может быть использована в качестве основы для систематизации лексики, причем не только по словообразовательным, но и по семантическим признакам, что вытекает из самого описания обобщенного инварианта СТ:

\begin{tabular}{|c|c|}
\hline $\begin{array}{l}\text { Обобщенный } \\
\text { инвариант СТ } \\
{[13]}\end{array}$ & $\begin{array}{l}\text { принадлежность производящего(-их) слова (слов) или } \\
\text { основы (основ) производящего(-их) слова (слов) к } \\
\text { одной и той же части речи } \\
\text { участие в словообразовательном акте форманта } \\
\text { конкретного а) по форме и б) по содержанию } \\
\text { принадлежность производного слова к одной и той же } \\
\text { части речи } \\
\text { выводимость абстрагированного } \\
\text { словообразовательного значения путем соотношений } \\
\text { конкретных лексических единиц: производное слово - } \\
\text { производящее слово }\end{array}$ \\
\hline
\end{tabular}

Как можно заметить, последняя часть обобщенного инварианта СТ отсылает нас к обобщенному значению производного слова, имеющему связь как с лексическим значением производящего слова, так и со словообразовательным значением форманта, принимающего участие в процессе деривации, что и может лечь в основу процесса систематизации производных терминов дизайна. 
При этом необходимо сделать акцент именно на производных терминах, поскольку данный метод систематизации использует непроизводную лексику только в качестве производящего элемента. Непроизводная лексика может систематизироваться и классифицироваться любым из названных выше способов.

Инвариант СТ лег в основу разработанных схем и построенных на их базе словообразовательных моделей, описанных в книге «Модели и схемы словообразовательных типов русского языка» [13]. Там же приводится подробное описание процесса построения словообразовательных моделей, состоящего из четырех частей-операций.

Исходя из разработанной М.Ш. Шекихачевой технологии, автором статьи была проведена работа по отбору непроизводной терминологической и профессиональной дизайнерской лексики и ее классификации по лексико-семантическим группам, выявлению наиболее продуктивных типов производных терминов, а также построению словообразовательных моделей производных терминов дизайна по наиболее продуктивным схемам СТ.

\section{Результаты и обсуждение}

Автором в процессе изучения профессиональной дизайнерской лексики были выделены следующие лексико-семантические группы: общенаучные термины, общетехнические термины, общеэстетические термины, общедизайнерские термины, дизайнерские термины по специализациям (дизайн городской среды, дизайн одежды, графический дизайн, промышленный дизайн и др.) и представлены их списки [15, с. 36-39].

Анализ схем словообразовательных типов выявил следующие наиболее продуктивные типы, использующиеся в образовании производной дизайнерской лексики: суффиксальные и сложные существительные, суффиксальные прилагательные, суффиксальные глаголы.

Из суффиксальных существительных были наиболее часто представлены следующие схемы: 


\section{1)}

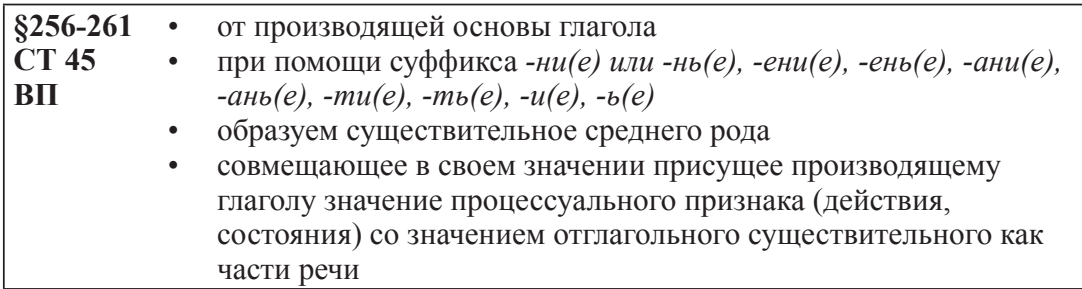

По данной схеме строятся модели:

I

модели́ро-

$8 a(m b)$ -

проекти́ровa(mb) -
II

моделирова+$н u(e)=$

проектирова+$н и(e)=$
III модели́рование -

проекти́рование -
IV

“действие по знач. глагола моделировать; процесс создания модели»

“действие по знач. глагола проектировать; процесс разработки, составления проекта»

2)

\begin{tabular}{|lll}
$\mathbf{\$ 3 3 5}$ & $\bullet$ & от производящей основы существительного \\
$\mathbf{C T ~} 134$ & $\bullet$ & при помощи суффикса -изм или -онизм \\
П & образуем существительное мужского рода \\
спец. терм., & $\bullet$ & со значением «общественно-политическое (научное, \\
газ.-публ. речь & $\begin{array}{l}\text { искусства) направление (или система качество, } \\
\text { склонность), связанное с тем, что названо производящим } \\
\text { словом» }\end{array}$ \\
\hline
\end{tabular}

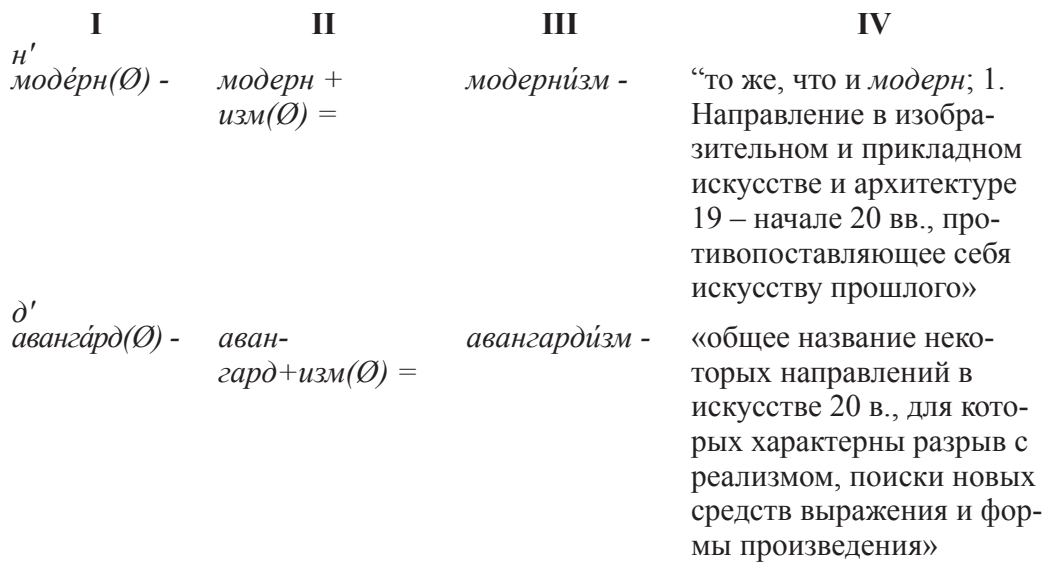




\section{3)}

\begin{tabular}{|c|c|}
\hline $\begin{array}{l}\S 263 \\
\text { СТ } 47 \\
\text { ВП } \\
\text { спец. и } \\
\text { научно-тех. } \\
\text { терм. }\end{array}$ & $\begin{array}{l}\text { - } \quad \text { от производящей основы глагола несовершенного вида } \\
\text { (преимущественно с иноязычной основой, на -ировать, } \\
\text {-изовать, реже на -овать) } \\
\text { - при помощи суффикса -аци(я) или -ици(я), енци(я), -изи(я), и(я) } \\
\text { - } \quad \text { образуем существительное женского рода } \\
\text { - совмещающее в своем значении присущее производящему } \\
\text { глаголу значение процессуального признака (действия, } \\
\text { состояния) со значением существительного как части речи }\end{array}$ \\
\hline
\end{tabular}

\section{I}

К๘страгИ́РО-

$B A(m b)-$

3

автоматизИ́РО-

$B A(m b)$ -
II

абстрак+-

$u u(я)=$

III

абстра́к-

цุия -

автома -

тиз + ации $(я)=$ автоматиза́ция-
IV

«мысленное отвлечение от тех или иных сторон, свойств или связей предмета с целью выделения существенных и закономерных признаков»

“действие по знач. глагола автоматизировать; применение, внедрение автоматических приборов, машин»

\section{4)}

$\begin{array}{lll}\$ 347 & \bullet & \text { от производящей основы существительного } \\ \text { CT 126 } & \bullet & \text { при помощи суффиксов -ер или -онер, -ьер, -ир } \\ \text { OП } & \bullet & \text { образуем существительное } \\ & \text { со значением «лицо по отношению к предмету (или } \\ & \text { учреждению, группировке), по характерному занятию } \\ & \text { (действию), названному производящим словом }\end{array}$

$H^{\prime}, \mathbf{I}$

I II

II III

IV

диза́йн(Ø) - дизайн + ер $(\varnothing)=$ диза́йнер - $\quad$ «художник-конструктор, специалист по художественному проектированию предметов, производимых промышленностью, а также интерьеров промышленных объектов, общественных зданий»

моде́ль (Ø) модель + ер $(\varnothing)=$ моделье́р “специалист по изготовлению моделей»» 
Среди сложных существительных наиболее распространенной является схема:

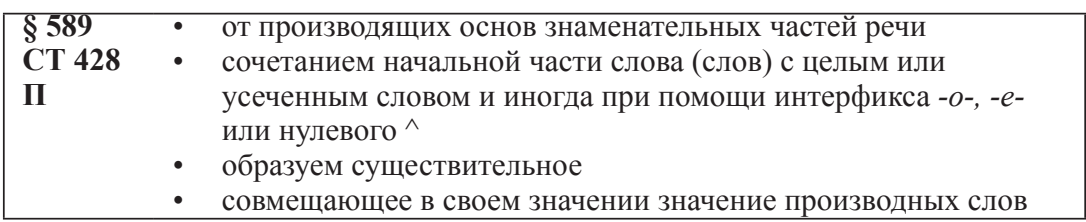

По данной схеме строятся модели:

I II III

футурИСТЙЧЕ- футур $+o+\partial u-\quad$ фу́mуроди-

СКИЙ диза́йн(Ø) - зайн(Ø)=

экоЛОГИ́ЧЕ- эко+^+

СКИЙ диза́йн(Ø) - зайн(Ø) = $\quad$ н(Ø) -

эргоНОМйЧЕ- эрго+^+ди- э́ргодиза́й-

СКИЙ диза́йн(Ø) - зайн(Ø) $=\quad$ н(Ø)-

IV
“проектирование объек-
тов, связанных с футу-
рологией, будущим»
“проектирование объ-
ектов, связанных с эко-
логией, отвечающих ее
требованиям»
“проектирование объек-
тов, связанных с эргоно-
микой, отвечающих ее
требованиям»

Наиболее продуктивной схемой построения производных суффиксальных прилагательных, относящихся именно к терминологической лексике, можно отнести следующую:

\begin{tabular}{|c|c|}
\hline $\begin{array}{l}\$ 617-622 \\
\text { СТ } 434 \\
\text { П }\end{array}$ & 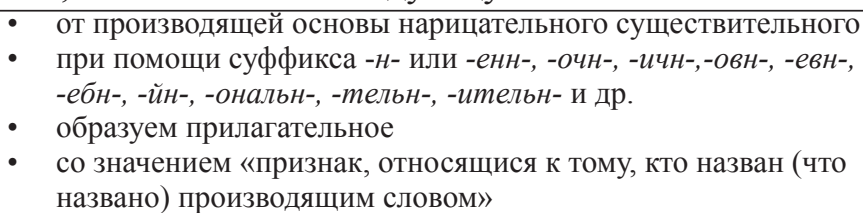 \\
\hline
\end{tabular}

По данной схеме строится большое количество словообразовательных моделей:

\begin{tabular}{|c|c|c|c|}
\hline $\begin{array}{l}\text { I } \\
\phi y ́ н \kappa- \\
u и(я)-\end{array}$ & $\begin{array}{c}\text { II } \\
\text { функии }+o- \\
\text { нальн(вій) }\end{array}$ & $\begin{array}{c}\text { III } \\
\text { функцио- } \\
\text { на́льный- }\end{array}$ & $\begin{array}{l}\text { IV } \\
\text { “1. прилаг. к функиия; 2. связанный с } \\
\text { проявлением жизнедеятельности ор- } \\
\text { ганизма, с отправлением функций» }\end{array}$ \\
\hline бло́к(Ø) - & $\begin{array}{l}\text { блоч }+ \\
н(\text { вій })=\end{array}$ & $\begin{array}{l}\text { бло́ч- } \\
\text { ный - }\end{array}$ & $\begin{array}{l}\text { “прилагательное к блок; относящийся } \\
\text { к блоку, состоящий из блоков» }\end{array}$ \\
\hline зе́к- & $\begin{array}{l}\text { век- } \\
\text { тор }+ \text { ны } ы \check{u})=\end{array}$ & $\begin{array}{l}\text { ве́ктор- } \\
\text { ньцй - }\end{array}$ & $\begin{array}{l}\text { “прилаг. к вектор; расположенный по } \\
\text { вектору, относящийся к нему»” }\end{array}$ \\
\hline
\end{tabular}


Не менее часто суффиксальные прилагательные строятся по схеме:

\begin{tabular}{|llc|}
\hline § 630- & $\bullet$ & от производящей основы существительного \\
$\mathbf{6 3 5}$ & - & при помощи суффикса -ск- или -еск-, -ическ-,-овск-, \\
CT 441 & евск-, -ческ-, инск-, -енск-, -анск-, -ийск-, -йск-, -нск-, -вск- \\
ВП & $\bullet$ & образуем прилагательное \\
& $\bullet$ & со значением «относящийся к тому (или свойственный \\
& тому), что названо (кто назван) производящим словом»
\end{tabular}

\begin{tabular}{|c|c|c|c|}
\hline I & II & III & IV \\
\hline $\begin{array}{l}\text { M' } \\
\text { алгори́m- } \\
\text { м(Ø)- }\end{array}$ & $\begin{array}{l}\text { алгоритм +u- } \\
\text { ческ(ий) = }\end{array}$ & $\begin{array}{l}\text { алгоритми́че- } \\
\text { ский - }\end{array}$ & $\begin{array}{l}\text { “прилаг. к алгоритм; } \\
\text { относящийся к алгорит- } \\
\text { му, присущий ему» }\end{array}$ \\
\hline $\begin{array}{l}M^{\prime} \\
\text { логари́ф }- \\
\text { м(ø)- }\end{array}$ & $\begin{array}{l}\text { логарифм }+u- \\
\text { ческ }(\text { ий })=\end{array}$ & $\begin{array}{l}\text { логарифми́че- } \\
\text { ский - }\end{array}$ & $\begin{array}{l}\text { “прилаг. к логарифм; от- } \\
\text { носящийся к логарифму, } \\
\text { содержащий его» }\end{array}$ \\
\hline
\end{tabular}

Суффиксальные глаголы, наиболее продуктивные в терминологической лексике, строятся по схеме:

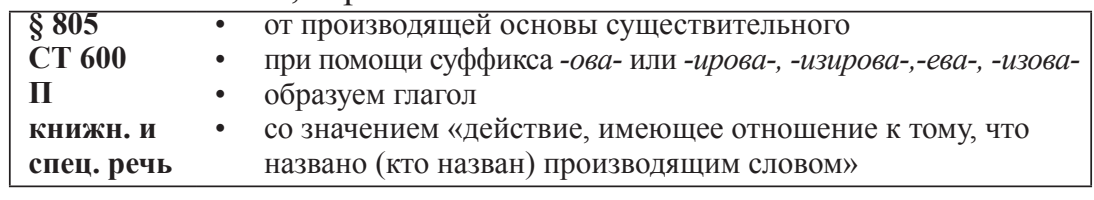

\begin{tabular}{|c|c|c|c|}
\hline I & II & III & IV \\
\hline $\begin{array}{l}m \\
\text { автома́т(ø) - }\end{array}$ & $\begin{array}{l}\text { автомат +изиро- } \\
в а(т ь)=\end{array}$ & $\begin{array}{l}\text { автомати- } \\
\text { зи́ровать - }\end{array}$ & $\begin{array}{l}\text { “применить, внедрить } \\
\text { автоматические при- } \\
\text { боры, машины» }\end{array}$ \\
\hline $\begin{array}{l}m^{\prime} \\
\text { annpém(ø)- }\end{array}$ & $\begin{array}{l}\text { annpem }+ \text { upo- } \\
в а(m b)=\end{array}$ & $\begin{array}{l}\text { аппрети́ро- } \\
\text { вать - }\end{array}$ & $\begin{array}{l}\text { «пропитать ткань, три- } \\
\text { котаж, специальным } \\
\text { средством для прида- } \\
\text { ния им особых свойств } \\
\text { (водонепроницаемо- } \\
\text { сти, несминаемости)» }\end{array}$ \\
\hline
\end{tabular}

Представленные выше модели и схемы производных терминов были выбраны, как уже было сказано, по принципу их продуктивности и частотности, но, конечно, не отражают все возможные варианты. Данные разработки нашли отражение в работах автора [15].

Методика, предлагаемая для систематизации производной терминологической лексики, обладает, как нам представляется, не только своей спецификой, но и рядом преимуществ, поскольку позволяет осу- 
ществлять комплексный подход: систематизировать слова как по словообразовательному принципу, так и по сходству лексического значения, связанному с общим значением словообразовательного аффикса.

\section{Заключение}

Исходя из вышеизложенного, можно сделать некоторые выводы:

1. Проблема систематизации и классификации терминологической лексики остается в настоящее время предметом научных исследований многих авторов.

2. Инвариант словообразовательного типа, являясь лингводидактической единицей, может быть использован в качестве средства систематизации терминологической лексики в силу ее специфических свойств.

3. В терминологической лексике дизайна могут быть выделены следующие лексико-семантические группы: общенаучные термины, общетехнические термины, общеэстетические термины, общедизайнерские термины, дизайнерские термины по специализациям.

4. Наиболее продуктивные схемы СТ производных дизайнерских терминов выделены среди суффиксальных и сложных имен существительных, суффиксальных имен прилагательных и суффиксальных глаголов.

Информация о конфликте интересов. Конфликт интересов не выявлен.

Информация о спонсорах. Статья печатается за счет средств автора. Благодарности. Автор выражает благодарность рецензентам.

\section{Список литературы}

1. Бахарлу Х., Алияри Ш.М., Шоджаи М. Основные способы и средства терминообразования в русской технической авиационной терминологии // Молодой ученый. № 11 (115), 2016. С. 1654-1659.

2. Буженинов А.Э. Синтаксический способ терминообразования (на материале гомеопатической терминологии русского и французского языков) // Инновации в науке. 2016. № 12-2 (61). С. 92-97.

3. Васильева О.А. Обучение специальной лексике студентов-медиков на занятиях по русскому языку: Автореферат дис. на соиск. учен. степ. канд. пед. наук (13.00.02.). М., 1980. 23 с. 
4. Винокур Г.О. О некоторых явлениях словообразования в русской технической терминологии // Труды МИФЛИ, т. 5. М., 1939. С. 3-55.

5. Воропаева В.С. Морфологический способ терминообразования в сфере аудита в итальянском и русском языках // Вестник ЧелГУ 2011. № 24. С. 64-66.

6. Головин Б.Н., Кобрин Р.Ю. Лингвистические основы учения о терминах. М.: Высш. шк., 1987. 104 с.

7. Гринев-Гриневич С.В. Терминоведение. М.: Издательский центр «Академия», 2008. 304 с.

8. Каргина Е.М. Метод систематизации лексики по смысловым группам при исследовании профессиональных иноязычных терминов // Совр. научные исследования и инновации. 2014. № 11. Ч. 3. [Эл.ресурс]. URL: http://web.snauka.ru/issues/2014/11/40943 (дата об-я: 02.02.2020).

9. Лейчик В.М. Терминоведение. Предмет. Методы. Структура. М.: Изд-во ЛКИ, 2007. 256 с.

10. Литовченко В.И. Классификация и систематизация терминов // Вестник Сибирского государственного аэрокосмического университета им. академика М.Ф. Решетнева. 2006. № 3 (10). С. 156-161.

11. Лотте Д.С. Основы построения научно-технической терминологии. М.: Изд-во АН СССР, 1961. 158 с.

12. Мкртчян Г.А. Вопросы методики обучения специальной лексике на уроках русского языка в СПТУ. Ереван: Луйс, 1990. 197 с.

13. Модели и схемы словообразовательных типов русского языка / М.Ш. Шекихачева, Н.В. Бочоришвили, Р.Х. Варквасова и др; Под ред. М.Ш. Шекихачевой. М.: Высш. шк., 1993. 496 с.

14. Семичев В.Н. Вопросы терминологического словообразования (на материале терминологии литературоведения): автореф. дис. на соиск. учен. степ. канд. филол. наук (10.02.01). М., 1968. 20 с.

15. Шонтукова И.В. Изучение профессиональной лексики дизайна на основе инварианта CT. Saarbrücken, Deutschland / Германия: LAP Lambert Academic Publishing, 2013. 169 с. (источник на русском языке).

\section{References}

1. Baharlu H., Aliyari S.M., Shojai M. Osnovnye sposoby i sredstva terminoobrazovanija v russkoj tehnicheskoj aviacionnoj terminologii [Main 
ways and means of term formation in Russian technical aviation terminology]. Molodoj uchenyj, no 11 (115), 2016, pp. 1654-1659.

2. Buzheninov A.E. Sintaksicheskij sposob terminoobrazovanija (na materiale gomeopaticheskoj terminologii russkogo i francuzskogo jazykov) [Syntactic method of term formation (based on the material of homeopathic terminology of Russian and French languages)]. Innovacii $v$ nauke. 2016, no 12-2 (61), pp. 92-97.

3. Vasileva O.A. Obuchenie special'noj leksike studentov-medikov na zanjatijah po russkomu jazyku [Teaching special vocabulary to medical students in the classroom in the Russian language]: Avtoreferat dis. na soisk. uchen. step. kand. ped. Nauk (13.00.02.). Moscow, 1980. 23 p.

4. Vinokur G.O. O nekotoryh javlenijah slovoobrazovanija v russkoj tehnicheskoj terminologii [On some phenomena of word formation in Russian technical terminology]. Trudy MIFLI, vol. 5. Moscow, 1939, pp. 3-55.

5. Voropaeva V.S. Morfologicheskij sposob terminoobrazovanija v sfere audita $\mathrm{v}$ ital'janskom i russkom jazykah [Morphological method of term formation in the field of audit in Italian and Russian languages] Vestnik ChelGU, 2011, no. 24, pp. 64-66.

6. Golovin B.N., Kobrin R.Yu. Lingvisticheskie osnovy uchenija o terminah [Linguistic bases of the terms doctrine]. Moscow: Vyssh. shk., 1987. 104 p.

7. Grinev-Grinevich S.V. Terminovedenie [Terminology studies]. Moscow: Izdatel'skij centr «Akademija», 2008. 304 p.

8. Kargina E.M. Metod sistematizacii leksiki po smyslovym gruppam pri issledovanii professional'nyh inojazychnyh terminov [Method of systematization of vocabulary by semantic groups in the study of professional foreign language terms]. Sovremennye nauchnye issledovanija i innovacii. 2014, no. 11. part 3. URL: http://web.snauka.ru/issues/2014/11/40943

9. Leychik V.M. Terminovedenie. Predmet. Metody. Struktura [Terminovedenie. Subject. Methods. Structure]. Moscow: Izd-vo LKI, 2007. 256 p.

10. Litovchenko V.I. Klassifikacija i sistematizacija terminov [Classification and systematization of terms]. Vestnik Sibirskogo gosudarstvennogo ajerokosmicheskogo universiteta im. akademika M.F. Reshetneva. 2006. No. 3 (10), pp. 156-161. 
11. Lotte D.S. Osnovy postroenija nauchno-tehnicheskoj terminologii [Bases of construction of scientific and technical terminology]. Moscow: Izdvo AN SSSR, 1961. 158 p.

12. Mkrtchyan G.A. Voprosy metodiki obuchenija special'noj leksike na urokah russkogo jazyka v SPTU [Methods of teaching special vocabulary at the Russian language lessons in SPTU]. Yerevan: Luys, 1990. 197 p.

13. Modeli i shemy slovoobrazovatel'nyh tipov russkogo jazyka [Models and schemes of word-forming types of the Russian language]. Moscow: Vyssh. shk, 1993. 496 p.

14. Semichev V.N. Voprosy terminologicheskogo slovoobrazovanija (na materiale terminologii literaturovedenija) [Questions of terminological word formation (on the material of terminology of literary studies)]: avtoref. dis. na soisk. uchen. step. kand. filol. nauk (10.02.01). Moscow, 1968. 20 p.

15. Shontukova I.V. Izuchenie professional'noj leksiki dizajna na osnove invarianta $S T$ [Studying the professional vocabulary of design based on the invariant ST]. Saarbrücken, Deutschland / Germany: LAP Lambert Academic Publishing, 2013. 169 p. (in Russian).

\section{ДАННЫЕ ОБ АВТОРЕ}

Шонтукова Ирина Васильевна, кандидат педагогических наук, доцент

Центр непрерывного повышения профессионального мастерства педагогических работников

Проспект Ленина, 8, г. Нальчик, 360000, Российская Федерация shonirina@yandex.ru

\section{DATA ABOUT THE AUTHOR}

Shontukova Irina Vasiljevna, Candidate of Pedagogical Sciences, Associate Professor

Center for Continuous Professional Development of Teachers

8, Lenin Ave., Nalchik, 360000, Russian Federation

shonirina@yandex.ru

SPIN-code: 8793-5324

ORCID: 0000-0002-7665-7215 